\title{
Disinfection of Endoscopy and Reusability of Accessories
}

\author{
Praveer Rai ${ }^{1}$ \\ ${ }^{1}$ Department of Gastroenterology, Sanjay Gandhi Postgraduate \\ Institute of Medical Sciences, Lucknow, Uttar Pradesh, India
}

\begin{abstract}
Address for correspondence Praveer Rai, MD, DM, Department of Gastroenterology, Sanjay Gandhi Postgraduate Institute of Medical Sciences, Lucknow 226014, Uttar Pradesh, India (e-mail: praveer_rai@yahoo.com).
\end{abstract}

\begin{abstract}
Corona viruses are a group of medium-sized positive-sense single-stranded RNA viruses with crown-like structure due to projections noted over the surface of the virus. The infection has been declared as a pandemic by the world health organization (WHO) in March 2020. Health care professionals in endoscopy are at high risk of infection by novel corona virus disease 2019 (COVID-19) from inhalation of droplets, conjunctival contact, feces, and touch contamination. Upper gastrointestinal $(\mathrm{Gl})$ endoscopy is considered to be a high-risk aerosol-generating procedures (AGPs) and the live virus has been found in patient stool. Flexible endoscopes when contaminated have been considered as the vector for transmission of infections. Infections related to the side viewing endoscopes and endoscopic ultrasound scopes are more frequent than upper Gl scope and colonoscopes. Stratifying patients needing endoscopy and deferral of elective procedures will help to decrease the virus spread. Planning and revision of workflows is necessary for safety of patient and staff and to successfully provide infection prevention and control measures, for this a "three zones and two passages" concept should be followed. Manual cleaning followed by high-level disinfection (HLD), effectively eliminates nearly all microorganisms from endoscopes during reprocessing. Transmission of viral infections during endoscopy is quite rare and, it is usually the result of noncompliance from the essential steps of reprocessing. Reuse of any disposable $\mathrm{Gl}$ endoscopic device is strongly discouraged. Environmental decontamination is essential to reduce the risk of fomite transmission. Noncritical environmental surfaces frequently touched by hands (e.g., bedside tables and bed rails) and endoscopy furniture and floor should be considered heavily contaminated in patients with intermedi-

Keywords

- disinfection

- COIVD-19

- endoscopy

- endoscopic accessories ate or high risk of COVID-19 and should be thoroughly disinfected at the end of each procedure. If available, negative pressure rooms are preferred for endoscopy, as has been advised by Centers for Disease Control and Prevention (CDC). Staff involved in reprocessing and the cleaning of endoscopy rooms should utilize personal protective equipment (PPE) including N95 mask. Reprocessing staff should undergo necessary training and ongoing annual assessment of competency.
\end{abstract}

\section{Introduction}

Corona viruses are a group of medium-sized positive-sense single-stranded RNA viruses with crown-like structure due to projections noted over the surface of the virus. ${ }^{1}$ Some coronavirus species are known to cause human disease and majority of these cause only mild respiratory disease. However, fatal coronavirus diseases have been reported earlier which includes severe acute respiratory syndrome-coronavirus (SARS-CoV) in 2002 and the Middle East respiratory syndrome-coronavirus (MERS-CoV) in 2012. In December 2019, a series of pneumonia cases were reported at Wuhan in China resulting from a novel coronavirus infection designated as SARS-CoV-2 and named novel coronavirus disease 2019 (COVID-19) by the World Health Organization (WHO) on February 11, 2020. ${ }^{2}$ 
The infection has been declared as a pandemic by the world health organization (WHO) in March 2020. There have been 2,074,529 confirmed cases of COVID-19, with 139,378 deaths affecting 213 countries as on April 17, 2020. ${ }^{3}$

The virus is transmitted from human to human primarily through respiratory secretions, in the form of droplets, while other modes include aerosols, feces, and contaminated environmental surfaces. ${ }^{4,5}$ Studies have shown that the virus particles can be detected in aerosols for up to 3 hours after aerosolization and up to 3 days on surfaces. ${ }^{6}$ Moreover, undocumented infections have been found to be the source of a significant majority of documented cases. ${ }^{7}$ Transmission can occur from both symptomatic and asymptomatic individuals

Health care professionals in endoscopy are at high risk of infection by COVID-19 from inhalation of droplets, conjunctival contact, feces, and touch contamination. ${ }^{2,8}$ Upper gastrointestinal (GI) endoscopy is considered to be a highrisk aerosol-generating procedures (AGPs) and the virus has been found in patient stool alive. ${ }^{5,8,9}$ Moreover, the infected health workers may transmit the infection to their patients. Infection prevention and control has been shown to be dramatically effective in assuring the safety of both health care professionals and patients.

\section{Gastrointestinal Endoscopy and Viral Transmission}

Flexible endoscopes when contaminated have been considered as the vector for transmission of infections. ${ }^{10}$ The exact burden of this problem is, however, unknown, possibly due to asymptomatic infections and incomplete surveillance. Health care-associated infection outbreaks have been reported and hence comprehensive endoscope cleaning strategies with high-level disinfection (HLD) and reprocessing has been recommended. ${ }^{11}$ Infections related to the side viewing endoscopes and endoscopic ultrasound scopes are more frequent than upper GI scope and colonoscopes. The majority of these infections are bacterial; however, the transmission of other microbial organisms have also been reported. ${ }^{12}$

Viral transmission through endoscopes has been reported with hepatitis B and C viruses. ${ }^{13}$ Though COVID-19 is predominately spread by respiratory droplets, the virus is also present in infected stools and, hence can result in viral transmission via aerosolization and fecal-oral route of contamination. Since the endoscopes are affected by gut flora, it poses a risk not only to the endoscopists, nurses, and other endoscopy staff but also could be a source of infection transmission to other patients. ${ }^{10}$ Till date, there is no reported case of endoscope-related COVID-19 transmission; however, the risk remains, especially with prior experiences with hepatitis $B$ and $C$ viruses. It is reassuring that post cleaning samples of SARS-CoV-2 became negative, indicating that current endoscope disinfection techniques are sufficient. ${ }^{14}$

\section{Disinfection, Handling, and Endoscope Storage}

\section{Endoscope}

Gastrointestinal endoscopes are semi critical devices (devices that contact the mucous membranes), and these devices require HLD to destroy microorganisms and prevent transmission of endoscopy related infection. Standard manual cleaning followed by HLD should be effective at eradicating SARS-CoV-2. ${ }^{14}$ Hence, no changes to the reprocessing of GI endoscopes are recommended. ${ }^{15,16}$ The reprocessing workflow as suggested by European Society of Gastrointestinal Endoscopy (ESGE) is shown in - Fig. $1 .^{15}$

Endoscope reprocessing is a multistage process including manual initial cleaning, HLD, rinsing, drying, and storage. The salient points of each step are highlighted and holds true for prevention of COVID-19 as well.

\section{Precleaning}

- Precleaning should commence in the procedure room and should be done by the staff already in the room.

- Manual cleaning of the endoscope is done with detergent solution and brushes after procedure completion to prevent drying of debris on or within the endoscope. ${ }^{16}$

- The insertion tube of the endoscope is wiped, and the channels are flushed with detergent according to the manufacturer's instructions.

- The air/water channel is purged to clear debris from the channel and thus avoid drying of debris on surfaces and removes microorganisms.

- After this, a properly labeled and an enclosed container is used for transportation of the endoscopes to the decontamination room

Leak testing: leak testing is performed to check the integrity of all channels.

\section{Manual Cleaning}

- Manual cleaning is performed before HLD.

- All debris is washed from its exterior by wiping and brushing after immersing the scope.

- A low-foaming medical grade detergent is used and is diluted according to the manufacturer's instructions. The scope remains immersed during the cleaning process.

- The suction and air/water valves, the biopsy channel cover, and all other removable parts are detached, while parts not intended for reuse are discarded. Brushing continues until there is no visible debris.

- For elevator channel endoscopes, it is important to ensure that the elevator mechanism located at the distal tip of the duodenoscope is thoroughly cleaned and free of all visible debris.

- After manual cleaning, the endoscope and all removable parts are thoroughly rinsed with clean water to remove residual debris and detergent. 


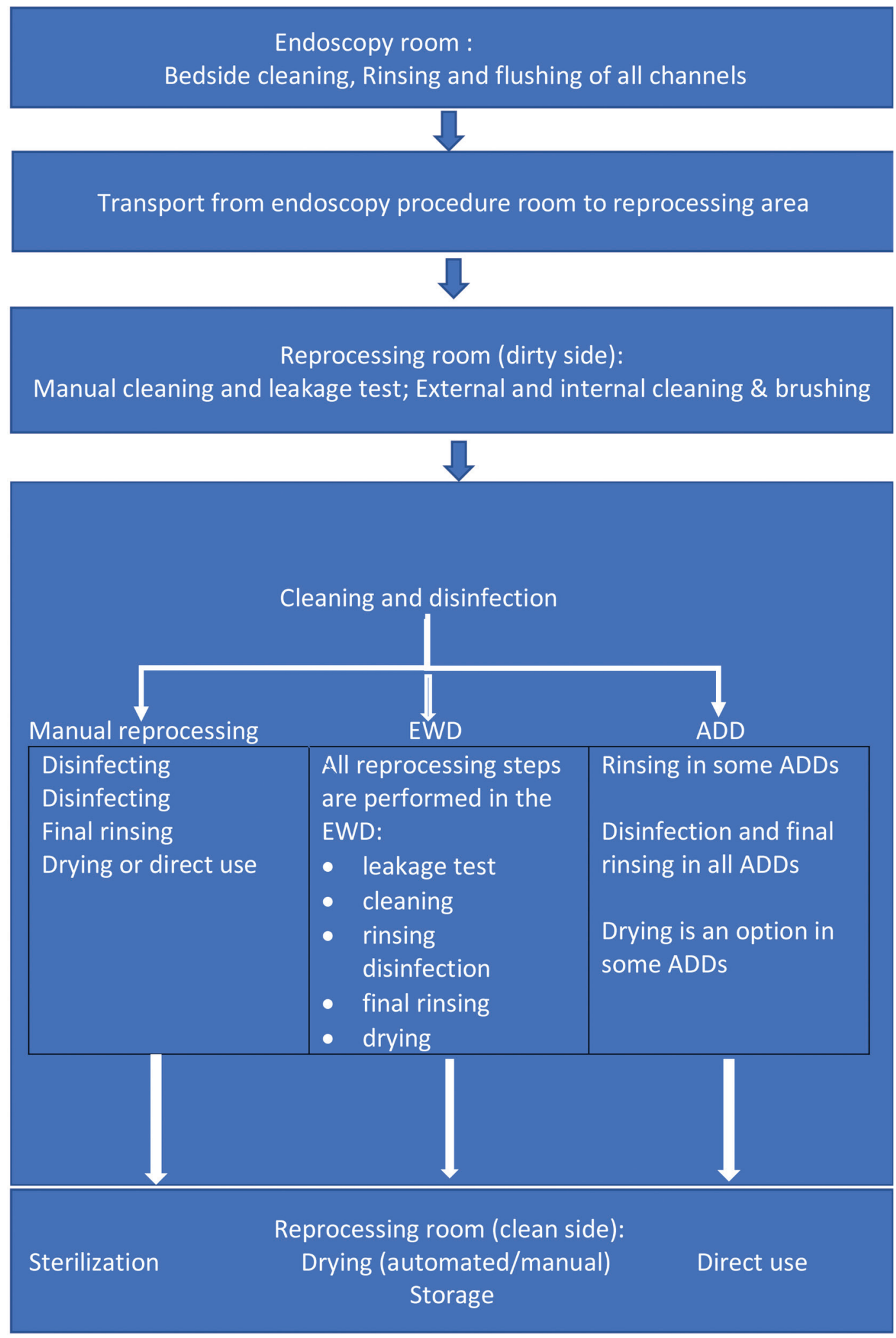

Fig. 1 Different phases of endoscope reprocessing. EWD, endoscope washer disinfector; ADD, automated disinfection device.

- Forced air is used to purge water from the channels. After manual cleaning, endoscopes and reusable accessories are visually inspected prior to HLD.

\section{High-Level Disinfection}

- HLD is the process of completely eliminating all microorganisms in or on a medical device, except for some of bacterial spores. 
- At most endoscopy centers, HLD is performed with a liquid chemical germicide solution by using an automated endoscope reprocessor that meets the standards of the Food and Drug Administration (FDA; or other government agency), while some centers use a manual process for HLD. ${ }^{16}$

- Different disinfectants used for this purpose should be tested according to the European Standard, EN 14885. The product used must be bactericidal, mycobactericidal, fungicidal, and viricidal against enveloped and nonenveloped viruses. The germicidal chemical used for HLD must be compatible with the manufacturer's instructions. Commonly used disinfectant is glutaraldehyde

Rinsing: After HLD, the endoscope surface, channels, and removable parts must be rinsed with clean, bacteria-free water. Rinsing prevents exposing skin or mucous membranes to chemical residue.

\section{Drying}

- Compressed air is used to purge water from the channels, then flushing the channels with alcohol, followed by a second forced-air drying. ${ }^{17}$

- Residual water in the channels after mixing with alcohol evaporates as air flows through the channels. If the channels and elevator mechanism are not completely dry, bacterial growth can occur resulting in persistent contamination. ${ }^{18}$

- The exterior of the endoscope is dried with a soft, clean, lint-free cloth.

\section{Storage and Reuse}

- There isn't any additional recommendation with regard to endoscope storage during the pandemic.

- A well-ventilated, dust-free, and forced-air drying cabinet is used to store the endoscopes. The endoscopes are stored in a vertical position with the tip hanging freely.

- Hence, although reuse within 21 days and perhaps even, 56 days appears to be safe, the data are insufficient to provide a maximal outer duration for use of appropriately cleaned, reprocessed, dried, and stored flexible endoscopes.

Certain other points that need to be implemented seeing the COVID-19 pandemic are as follows ${ }^{19}$ :

- Limit the number of reprocessing staff.

- Reprocessing staff should be experienced with documented competency.

- All endoscopes should undergo full standard reprocessing prior to return to the endoscope manufacturer for maintenance.

- Reprocessing staff should have proper personal protective equipment (PPE). ${ }^{20}$ The use of $\mathrm{N} 95$ respirators in the reprocessing room should be considered, if available.

- Clean gloves should be worn while transporting dry endoscopes to storage or drying cabinet

\section{Endoscopic Accessories}

- Reprocessing of endoscopic accessories should be performed according to published guidelines. ${ }^{15}$ However, reuse of any disposable GI endoscopic device is strongly discouraged. ${ }^{21}$

- Sterilization is required for reusable accessories (e.g., biopsy forceps, snares, and sphincterotomes) that breach the mucosal barrier.

- The water bottle and its connecting tube are typically changed at least daily, and the water bottle and tubing are sterilized after use (or discarded if it is single-use only)

\section{Room Cleaning Process}

- Environmental decontamination is essential to reduce the risk of fomite transmission.

- Meticulous cleaning of all high-touch and horizontal surfaces in procedure rooms after each procedure with an environment protection agency (EPA) approved surface disinfectant. ${ }^{22}$ Some of these disinfectants include hydrogen peroxide, sodium hypochlorite, chlorine dioxide, and others. The contact time ranges from 1 to 10 minutes.

- Noncritical environmental surfaces frequently touched by hands (e.g., bedside tables and bed rails) and endoscopy furniture and floor should be considered heavily contaminated in patients with intermediate or high risk of COVID-19 and should be thoroughly disinfected at the end of each procedure.

- The cleaning process should include cleaning of all surfaces in the procedure room to remove all soil and biofilm, followed by proper disinfection, as clearly reported in the ASGE (American Society of Gastrointestinal Endoscopy) guideline. $^{16}$

- Standard room disinfection policy should be kept in rooms where non-COVID-19 or low-risk patients undergo endoscopy. For surface and noncritical patient care equipment disinfection, 1:100 dilution of household bleach and water can be used. ${ }^{23}$

- If available, negative pressure rooms are preferred, as has been advised by Centers for Disease Control and Prevention (CDC). ${ }^{24}$ In negative-pressure rooms, a delay of approximately 30 minutes is suggested before allowing a new patient to enter the room. Because small particles remain airborne for some period of time, in the absence of negative-pressure rooms, alternative measures such as diluting the air with cleaner air from the outdoors should be considered and the room kept empty for at least 1 hour.

- Staff involved in the cleaning of endoscopy rooms should utilize complete PPE.

- Each endoscopy unit should have a plan in place for the cleaning and disinfecting of the entire unit at the end of the day.

\section{Quality Assurance}

Quality assurance is essential for the effectiveness and safety of endoscope reprocessing protocols. Documenting the monitoring process typically includes the following: 
- Procedure date and time.

- Patient's name and medical record number.

- Endoscopist's name.

- Endoscope model and serial number.

- Automatic endoscope reprocessor (if used) model and serial number.

- Names of technicians who reprocessed the endoscope.

Waste management: contaminated waste and endoscopic devices from high-risk patients, or with suspected or confirmed COVID-19 should be disposed of using the specific local regulations related to high-risk waste. ${ }^{21}$

Besides the disinfection in endoscopy, planning and revision of workflows is necessary for safety of patient and staff and to successfully provide infection prevention and control measures. "Three zones and two passages" concept should be followed: a contaminated zone, a potentially contaminated zone, and a clean zone should be clearly demarcated, with proper buffer areas in between. ${ }^{25}$ One-way passages for the transportation of contaminated equipment (such as endoscopes) are needed to avoid cross-contamination with clean equipment. Endoscopy unit layouts need to be adjusted to separate gown-up and gown-down areas to prevent cross-contamination. Separation in space and/or time between suspected and confirmed COVID-19 patients and other patients should be arranged.

GI endoscopes could pose a potential risk for transmission of viruses, and they could also theoretically transmit COVID19, especially in patients with fecal shedding. Even asymptomatic individuals have shown to shed virus in feces, which can last many days after resolution of symptoms. Stratifying patients needing endoscopy and deferral of elective procedures will help to decrease the virus spread. Manual cleaning, followed by HLD, effectively eliminates nearly all microorganisms from endoscopes during reprocessing. ${ }^{26}$ Transmission of viral infections during endoscopy is quite rare and, it is usually the result of noncompliance from the essential steps of reprocessing.

Reprocessing of GI endoscopes has been outlined in several guidelines and should follow endoscope manufacturer instructions for use. ${ }^{27-29}$ Reprocessing staff should undergo necessary training and ongoing, annual assessment of competency. It would be prudent at this time for endoscopy unit leadership to reemphasize the importance of optimal reprocessing and ensure competency assessments are up to date.

\section{Conflict of Interest}

There is no conflict of interest.

\section{References}

1 Wang C, Horby PW, Hayden FG, Gao GF. A novel coronavirus outbreak of global health concern. Lancet 2020;395(10223) :470-473

2 Huang C, Wang Y, Li X, et al. Clinical features of patients infected with 2019 novel coronavirus in Wuhan, China. Lancet 2020;395(10223) :497-506

3 Coronavirus disease (COVID-2019) situation reports. Available at: https://www.who.int/emergencies/diseases/ novel-coronavirus-2019/situation-reports. Accessed April 23, 2020

4 Del Rio C, Malani PN. COVID-19-new insights on a rapidly changing epidemic. JAMA 2020;(e-pub ahead of print) doi $10.1001 /$ jama.2020.3072

5 Xiao F, Tang M, Zheng X, Liu Y, Li X, Shan H. Evidence for gastrointestinal infection of SARS-CoV-2. Gastroenterology 2020; (epub ahead of print) doi 10.1053/j.gastro.2020.02.055

6 van Doremalen N, Bushmaker T, Morris DH, et al. Aerosol and surface stability of SARS-CoV-2 as compared with SARSCoV-1. N Engl J Med 2020;382(16):1564-1567

7 Li R, Pei S, Chen B, et al. Substantial undocumented infection facilitates the rapid dissemination of novel coronavirus (SARSCoV2) Science 2020;(e-pub ahead of print) doi 10.1126/science.abb3221

8 Gu J, Han B, Wang J. COVID-19: Gastrointestinal manifestations and potential fecal-oral transmission. Gastroenterology 2020;(e-pub ahead of print) doi 10.1053/j.gastro.2020.02.054

9 Parodi SM, Liu VX. From containment to mitigation of COVID19 in the US. JAMA 2020;323(15):1441-1442

10 Rahman MR, Perisetti A, Coman R, Bansal P, Chhabra R, Goyal H. Duodenoscope-associated infections: update on an emerging problem. Dig Dis Sci 2019;64(6):1409-1418

11 US FDA. Infections associated with reprocessed duodenoscopes. Available at: https://www.fda.gov/medical-devices/ reprocessing-reusable-medical-devices/infections-associated-reprocessed-duodenoscopes Accessed April 23, 2020

12 Rutala WA, Weber DJ. Outbreaks of carbapenem-resistant Enterobacteriaceae infections associated with duodenoscopes: what can we do to prevent infections? Am J Infect Control 2016;44(5, suppl) :e47-e51

13 Kovaleva J, Peters FT, van der Mei HC, Degener JE. Transmission of infection by flexible gastrointestinal endoscopy and bronchoscopy. Clin Microbiol Rev 2013;26(2):231-254

14 Kampf G, Todt D, Pfaender S, Steinmann E. Persistence of coronaviruses on inanimate surfaces and their inactivation with biocidal agents. J Hosp Infect 2020;104(3):246-251

15 Beilenhoff $\mathrm{U}$, Biering H, Blum R, et al. Reprocessing of flexible endoscopes and endoscopic accessories used in gastrointestinal endoscopy: Position Statement of the European Society of Gastrointestinal Endoscopy (ESGE) and European Society of Gastroenterology Nurses and Associates (ESGENA) - Update 2018. Endoscopy 2018;50(12):1205-1234

16 Calderwood AH, Day LW, Muthusamy VR, et al; ASGE Quality Assurance in Endoscopy Committee. ASGE guideline for infection control during GI endoscopy. Gastrointest Endosc 2018;87(5):1167-1179

17 Barakat MT, Huang RJ, Banerjee S. Comparison of automated and manual drying in the elimination of residual endoscope working channel fluid after reprocessing (with video) Gastrointest Endosc 2019;89(1):124-132.e2

18 Muscarella LF. Inconsistencies in endoscope-reprocessing and infection-control guidelines: the importance of endoscope drying. Am J Gastroenterol 2006;101(9):2147-2154

19 SAGES webmaster: returning to operations after COVID-19. Available at: https://www.sages.org/author/sages-webmaster/ Accessed April 23, 2020

20 Joint Gastroenterology Society Message. COVID-19 Use of Personal Protective Equipment in GI Endoscopy Available at: https://els-jbs-prod-cdn.jbs.elsevierhealth.com/pb/assets/ raw/Health\%20Advance/journals/ymge/Joint_GI_Society_ Message_412020-1585850816173.pdf. Accessed March 30, 2020

21 ESGE and ESGENA Position Statement on gastrointestinal endoscopy and the COVID- 19 pandemic. Available at: https://www.esge.com/assets/downloads/pdfs/general/ESGE_ ESGENA_Position_Statement_gastrointestinal_endoscopy_ COVID_19_pandemic.pdf. Accessed April 23, 2020 
22 EPA Disinfectants for Use Against SARS-CoV-2. Available at: https://www.epa.gov/pesticide-registration/list-n-disinfectants-use-against-sars-cov-2.. Accessed March 30, 2020

23 Repici A, Maselli R, Colombo M, et al. Coronavirus (COVID-19) outbreak: what the department of endoscopy should know. Gastrointest Endosc 2020;(e-pub ahead of print) doi 10.1016/j. gie.2020.03.019

24 CDC Interim Infection Prevention and Control Recommendations for Patients with Suspected or Confirmed Coronavirus Disease. 2019 (COVID-19) in Healthcare Settings. Available at: https:// www.cdc.gov/coronavirus/2019-ncov/hcp/infection-control-recommendations.html?CDC_AA_refVal=https\%3A\%2F\%2Fwww.cdc. gov\%2Fcoronavirus\%2F2019-ncov\%2Finfection-control\%2Fcontrol-recommendations.html. Accessed April 23, 2020

25 Handbook of COVID-19 Prevention and Treatment. The First Affiliated Hospital, Zhejiang University School of Medicine, China
26 Kovaleva J. Infectious complications in gastrointestinal endoscopy and their prevention. Best Pract Res Clin Gastroenterol 2016;30(5):689-704

27 Petersen BT, Cohen J, Hambrick RD III, et al; Reprocessing Guideline Task Force. Multisociety guideline on reprocessing flexible GI endoscopes: 2016 update. Gastrointest Endosc 2017;85(2):282-294.e1

28 SocietyofGastroenterology Nursesand Associates(SGNA)Practice Committee. Standards of infection prevention in reprocessing of flexible gastrointestinal endoscopes. Available at: https:// www.sgna.org/Portals/0/SGNA Standards of infection prevention in reprocessing_FINAL.pdf?ver=2018-11-16-084835-387. Accessed March 30, 2020

29 ANSI/AAMI ST91. 2015 Flexible and semi-rigid endoscope processing in health care facilities. Available at: https://my.aami. org/aamiresources/previewfiles/ST91_1504_preview.pdf. Accessed March 30, 2020 